\title{
Portugueses no vale do café - indícios de formação de uma rede de sociabilidades
}

\section{Portuguese in the coffee valley - evidence of the formation of a network of sociabilities}

\author{
DOI: 10.46814/lajdv3n4-035
}

Recebimento dos originais: 01/05/2021

Aceitação para publicação: 31/06/2021

\begin{abstract}
Raimundo César de Oliveira Mattos
Doutor em História (UERJ); Professor Titular do Centro Universitário de Valença - UNIFAA; raimundomattos@bol.com.br; (24) 2452-5459 -(24) 9913-9141 - Rua Domingos Cosati, 485 -Centro -Valença $-\mathrm{RJ}$
\end{abstract}

\begin{abstract}
RESUMO
Aos portugueses que aportavam no Brasil desde o século XVI foram impostas novas condições de vida às quais tiveram que se adaptar destacando-se, aqui, o período imediatamente seguinte à emancipação política e o da formação da boa sociedade do Vale do Paraíba Fluminense a partir da exploração cafeeira, formando redes de sociabilidades e estratégias de poder. Nesta região, durante o oitocentos, podem ser identificados alguns indícios dessas redes, mediante a análise de jornais, documentos privados e outros. É o que propõe o estudo realizado por esse artigo.
\end{abstract}

Palavras-chave: Portugueses, sociabilidades, redes de poder.

\begin{abstract}
New life conditions were imposed to the Portuguese who landed in Brazil since the 16thcentury, conditions to which they had to adapt themselves, particularly, here, during the period that followed the political emancipation and the formation of the good society of the Paraiba Valley in Rio de Janeiro State based on thecoffee plantations, establishing webs of sociability and strategies of power. In this region, during the 1800s, some signs of these webs can be identified, through the analysis of newspapers, private documents and others. That is what is intended in the study carried on for this article.
\end{abstract}

Keywords: Portuguese, social networks, power network

\section{INTRODUÇÃO:}

A região do Vale do Paraíba Fluminense recebeu uma grande quantidade de migrantes portugueses no século XIX que se estabeleceram em diversas atividades, notadamente o comércio. Esses elementos, no entanto, precisaram lançar mão de diversificadas estratégias de sociabilidade para angariarem o respeito da boa sociedade local e passarem a fazer parte dessa mesma sociedade.

No caso de Valença, cidade do interior da província fluminense, desenvolvida no Império com a produção cafeeira, destacamos alguns elementos que se notabilizaram na construção de uma rede de sociabilidades: os integrantes das famílias Pimentel e Esteves, em especial Joaquim Gomes Pimentel, 
o Visconde de Pimentel, filho do açoriano Francisco Martins Pimentel e seu cunhado, o Comendador Manoel Antônio Esteves, proveniente da região do Minho.

Existem indícios da construção de uma rede de sociabilidades tecida por esses elementos e outros que, na busca do pertencimento a uma sociedade que era formada por famílias tradicionais. Obtenção de títulos de nobreza, participação em associações religiosas como irmandades, menções em jornais locais e nacionais eram estratégias utilizadas por eles que se articulavam entre si e deixaram pistas de tal procedimento.

\section{OBJETIVOS:}

- Demonstrar a existência de uma rede de sociabilidades ligando os portugueses do Vale do Paraíba Fluminense, em especial da cidade de Valença;

- Analisar as estratégias utilizadas por tais elementos para construírem essa rede de sociabilidades.

A região do Vale do Paraíba Fluminense recebeu uma grande quantidade de migrantes de origem portuguesa e seus descendentes, entre os quais muitos receberam sesmarias e constituíram o grupo de pioneiros na ocupação do território. A ação de tais elementos e o papel que desempenharam, bem como a sua importância no quadro local durante o oitocentos, precisa ser melhor esclarecida. Ao considerarmos o cenário citado, mediante a análise de cartas, jornais e outros, podemos encontrar indícios que nos levam a apontar a formação de uma rede de sociabilidades organizada por tais elementos, em uma tentativa de inserção na — boa sociedadell local. São os - fios de um tapetell, nas palavras de Ginzburg ${ }^{1}$. Segundo ele, —se a realidade é opaca, existem zonas privilegiadas -sinais, indícios -que permitem decifrá-la². Por essa razão optamos por adotar o indiciarismo no intuito de desvendarmos a chave de atuação dos portugueses que se fixaram no Vale do Paraíba Fluminense no século XIX, atuando, discretamente ou não, nesta sociedade que tinha os seus valores próprios e que, em uma primeira análise, não abria facilmente para novos membros. Necessário se fazia, desta forma, de apelar para estratégias de poder mediante a formação de sociabilidades. Após a independência, um grande número de portugueses passou para o Brasil, fato este constatado por diversos autores:

Segundo Herbert Klein, quase dois milhões de portugueses emigraram para o Brasil após a sua independência em 1822. Entre 1822 e 1950, estima-se que mais de 1.200 .000 portugueses tivessem chegado àquele país. Destes, pensamos que $80 \%$, ou seja, 960 mil, seriam oriundos do Norte de Portugal. ${ }^{3}$

\footnotetext{
${ }^{1}$ GINZBURG, Carlo. Mitos, Emblemas, Sinais. São Paulo: Companhia das Letras, 2007, p. 170.

${ }^{2}$ Ibid., p. 177.

${ }^{3}$ SOUSA, Fernando de. A emigração do Norte de Portugal para o Brasil: uma primeira abordagem (1834-1950). In: MATOS, Maria Izilda; SOUSA, Fernando de.; HECKER, Alexandre. Deslocamentos e Histórias: os portugueses. Bauru: EDUSC, 2008, p. 30
} 
Isso continuou o processo migratório ocorrido desde o período da colonização. A maior parte desses migrantes era proveniente da região dos Açores e do Minho:

Com o início de um novo século, a tendência desenhada anteriormente não foi alterada. Com efeito, a partir do registro de passaportes, verificamos que, após os anos de 1798 a 1806 , durante os quais não foi emitido qualquer passaporte, no período que vai de 1807 a 1820 registramos 250 passaportes, correspondendo a um total de 474 indivíduos, situando-se o pico da emissão de documentos em 1812, com 57 passaportes. Quanto à origem dos emigrantes, a maioria era da Terceira (188) e do Faial (173), seguindo-se os naturais de São Miguel (57) e alguns de Santa Maria (6). ${ }^{4}$

O Minho terá sido a região portuguesa de onde saiu mais gente para o Brasil, desde a colonização até a emigração massiva do século XIX, tendo esta última, alterado profundamente a face social e econômica da região.(...)

Gerações sucessivas de minhotos marcaram estreita ligação com o Brasil, levando para a excolônia um capital humano apreciável, com repercussões na pirâmide etária e na malha social do Minho. ${ }^{5}$

Sabe-se que o comércio sempre foi uma das principais atividades dos imigrantes, como meio de sustento, especialmente os portugueses, mesmo em áreas de fronteira agrícola.

Havia todo um cuidado por parte de comerciantes já estabelecidos no Brasil, no sentido de amparar o trabalho de conterrâneos que se dispunham a assumir encargos, em especial parentes vindos da Europa, o que dá origem a uma grande rede comercial e familiar por variadas áreas da Colônia. Muitos portugueses embarcaram para o Brasil, embalados pela ideia da riqueza, embora nem todos tenham conseguido alcançar seus objetivos, contentando-se em viver do que fosse possível.

No início do século XIX já encontrávamos grande número de portugueses no Rio de Janeiro exercendo importantes funções conforme assinala Gladys Ribeiro:

Os trabalhadores portugueses exerciam importantes tarefas na cidade do Rio de Janeiro, no início do século XIX, contrariando a historiografia que tem afirmado largamente ser a mão-deobra nesta época exclusivamente escrava ou liberta. Fora o hábito de empregar-se lusitanos na Marinha e no Exército, encontramos trabalhadores portugueses e luso-brasileiros em toda a documentação do período...6

\footnotetext{
${ }^{4}$ RODRIGUES, José Damião; ROCHA, Gilberto Pavão Nunes. A emigração açoriana para o Brasil:ritmos e destinos. In: MATOS, Maria Izilda; SOUSA, Fernando de.; HECKER, Alexandre (orgs.). Deslocamentos e Histórias: os portugueses. Bauru: EDUSC, 2008, p. 255

${ }^{5}$ FERNANDES, Adília.; PAIVA, Odete. Emigração dos minhotos para o Brasil (1850-1910).Os bem sucedidos e os outros. In: SOUSA, Fernando; MARTINS, Ismênia.; MATOS, Izilda (orgs.). Nas duas margens. Os portugueses no Brasil. Porto: CEPESE, 2009, p. 411.

${ }^{6}$ RIBEIRO, Gladys Sabina. Perfil do imigrante português nos códices de legitimação e apresentação de passaportes na Polícia -Arquivo Nacional do Rio de Janeiro. In: MARTINS, Ismênia de Lima.; SOUSA, Fernando. Portugueses no Brasil: Migrantes em Dois Atos. Rio de Janeiro: Muiraquitã, 2006, p. 54.
} 
Majoritários nas comunidades de negociantes estrangeiros, os portugueses encontravam-se, no Brasil, integrados de imediato pela língua e pela rede familiar e cultural tecida ao longo de dez gerações na América portuguesa. A esse respeito, Luiz Felipe de Alencastro levanta a seguinte questão: —como os moradores da América portuguesa, todos súditos do rei de Portugal, tornaram-se brasileiros de um dia para o outro após a Independência ${ }^{7}$ Feita a separação política do Brasil de Portugal, cada qual optou, por motivos quase que essencialmente particulares, em ficar no Brasil ou em voltar para Portugal. No caso dos comerciantes, houve uma atitude diferenciada, de acordo com Alencastro:

Todos os que tinham comércio, negócio de importação e de distribuição de importados, tomaram uma atitude oposta. Depositários de bens imóveis e exercendo o comércio por consignação, ou seja, ganhando uma comissão sobre mercadorias alheias que lhes eram confiadas para ser vendidas no Brasil, eles continuavam submetidos às casas comerciais do Porto e de Lisboa. Não convinha, nem aos seus patrões metropolitanos, nem a eles próprios, optar pela nacionalidade brasileira. O setor será, aliás, constantemente renovado pela vinda organizada de parentes portugueses que chegam como caixeiros para assumir, mais tarde, a sucessão do comerciante estabelecido na corte e nos principais portos brasileiros. Desse modo, a comunidade dos comerciantes portugueses no Brasil reproduz-se, ao longo do século XIX, no âmbito de um universo delimitado, cujo centro financeiro e mercantil situa-se no Porto e cujas bases demográficas residem na província do Minho, plataforma da imigração de caixeiros. ${ }^{8}$

Diversas foram, sem dúvida, as formas seguidas por estes imigrantes para alcançar os objetivos de enriquecimento, e podemos seguir a trajetória individual de alguns que exemplificam as soluções possíveis. Decorridos os primeiros anos após a independência, vencidas as desconfianças de não poucos brasileiros em relação aos reais interesses dos portugueses que continuaram no país recémseparado de Portugal, muitos desses conseguiam casamentos com filhas de produtores mais enriquecidos. A possibilidade de crédito, sem dúvida, foi um fator que facilitava a tramitação de tais matrimônios. A manutenção das fortunas rurais não era possível sem crédito. O português comerciante era garantia de novos empréstimos, trazidos por ele e por sua inserção no mercado, além de no comércio estar o acesso aos escravos, aos alimentos, aos mecanismos de produção agrícola, aos tecidos para vestimentas, enfim, a tudo aquilo de que os produtores rurais tinham necessidade para o funcionamento de suas fazendas e mesmo de suas vidas. Tal comportamento reflete o costume, herdado de Portugal e mantido de forma sistemática no Vale do Paraíba, de se organizarem redes de sociabilidade.

As aldeias e cidades localizadas próximas ao Paraíba atraíram portugueses de diversos grupos e classes. "No entanto, constata-se um afluxo de imigrantes portugueses para o Vale do Paraíba

${ }^{7}$ Cf. ALENCASTRO, Luiz Felipe de.; RENAUX, Maria Luíza. Op. cit. p. 307

8 ALENCASTRO, Luiz Felipe de.; RENAUX, Maria Luíza. Caras e modos dos migrantes e imigrantes. In: ALENCASTRO, Luiz Felipe de (org.). História da vida privada no Brasil. Império: a corte e a modernidade nacional. São Paulo, Cia das Letras, 1998, pp. 308-309. 
Fluminense para a formação de colônias agrícolas". ${ }^{9}$ Essa região foi sendo ocupada por tais elementos que chegavam em fluxos migratórios não somente como lavradores, mas também desempenhando outras atividades em função do desenvolvimento da região. Ilustrativo da presença e da importância dos portugueses na cidade de Valença é o fato de o primeiro presidente da Câmara Municipal, o Comendador Silveira Vargas, ser português.

A migração lusa, entretanto, para a província do Rio de Janeiro, vinha atender a uma série de necessidades:

Com um importante crescimento agrícola, era urgente a construção de estradas, vias férreas e pontes sobre os rios para o transporte e escoamento de sua produção agrícola, e a ampliação de suas instalações portuárias e sua infraestrutura urbana. (...) Foi para esse tipo de trabalho que se destinou com mais frequência a população de imigrantes portugueses que chegava à Província do Rio de Janeiro, não somente entre as décadas de 1830 e 1840, como identificou Luiz Felipe de Alencastro, mas durante todo o transcurso do século XIX, como demonstram inúmeros documentos do acervo do APERJ. ${ }^{10}$

Tal informação é confirmada, no mesmo livro, Portugueses no Brasil, mais adiante, por outra autora ao afirmar que "notadamente o Rio de Janeiro concentrou o maior contingente de imigrantes portugueses no país e foi, por muito tempo, a segunda maior cidade de população portuguesa no mundo, depois de Lisboa". ${ }^{11}$ A respeito dos estudos sobre migração e sua contribuição para a historiografia, bem como a mudança do enfoque dado, expõe Andréa Telo da Corte que:

Assim, no lugar do imigrante quantificado, despessoalizado e da história homogênea, a proliferação das histórias de vida e imigrantes, a partir da construção de fontes orais e da análise de documentos escritos, iconográficos e até mesmo videográficos, guardados nas gavetas e álbuns dos homens comuns, permite, conforme escreveu Maria Izilda Matos, a emergência de histórias até então inatingíveis residentes no cotidiano‘, possibilitando se não o resgate, pelo menos o acesso direto ao emaranhado de relações sociais, ações, negociações, resistências e estratégias de sobrevivência através das quais os grupos étnicos/sociais tecem suas vidas. ${ }^{12}$

Em Vassouras, segundo Stein, os portugueses foram o maior grupo imigrante livre e eram negociantes, médicos, advogados, professores e, em um status mais inferior, vendedores, feitores de fazendas e trabalhadores habilitados ou não. ${ }^{13}$ Até a chegada dos mais recentes, que puderam morar em bairros melhores, eles viviam nos arredores da cidade, local que ficou conhecido como "O Valão

\footnotetext{
${ }^{9}$ ASSIS, Charleston José de Sousa; DUARTE, Leila Menezes; MENDES, Anderson Fabrício Moreira. Fontes para o estudo da imigração portuguesa no arquivo público do estado do Rio de Janeiro. In: MARTINS, Ismênia de Lima.; SOUSA, Fernando. Portugueses no Brasil: migrantes em Dois Atos. Rio de Janeiro: Muiraquitã, 2006, p. 30.

${ }^{10}$ ASSIS, Charleston José de Souza; DUARTE, Leila Menezes; MENDES, Anderson Fabrício Moreira. Fontes para o Estudo da Imigração Portuguesa no Arquivo Público do Estado do Rio de Janeiro. Op. Cit., p 30

${ }^{11}$ KUSHNIR, Beatriz. Traços lusos nos acervos do Arquivo Geral da Cidade do Rio de Janeiro. In: MARTINS, Ismênia de Lima; SOUSA, Fernando. Portugueses no Brasil: Migrantes em Dois Atos. Rio de Janeiro: Muiraquitã, 2006, p. 45.

${ }^{12}$ CORTE, Andréa Telo da. Histórias de vida e imigração: as formas do passado. In: MATOS, Maria Izilda; SOUSA, Fernando de; HECKER, Alexandre. Deslocamentos e histórias: os portugueses. Bauru: EDUSC, 2008. p. 156.

${ }^{13}$ Cf. STEIN, Stanley J. Op. cit., p. 160-161.
} 
Português". Muitos eram originários dos Açores e, do continente, da região de Trás-os-Montes. Sobre um negociante, nascido na Madeira em 1832, conforme informa Stanley Stein, tendo começado como vendedor em uma loja da cidade aos15 anos de idade, acabou se tornando o mais rico negociante do local, tendo educado um filhona Escola de Direito de São Paulo. ${ }^{14}$

Analisando a migração portuguesa para a vizinha cidade de Vassouras, Roselene Martins chega a uma conclusão que pode ser também aplicada à Valença - a importância do fato de terem vindo os migrantes portugueses diretamente do Rio de Janeiro para o Vale:

O fato de terem desembarcado no Rio de Janeiro e terem vindo direto para Vassouras também é significativo. Era a possibilidade de riqueza que despertava a grande atração de imigrantes por estas terras. Além disso, como relatou o Dr. Antonio Lazzarine, importante médico imigrante e proprietário de terras de café e de maquinários para o beneficiamento de arroz, no jornal O Município, de 1874,os portugueses eram considerados trabalhadores resistentes, conscientes do valor do dinheiro e dignos de confiança. Traziam, depois de algum tempo, seus parentes e/ou conterrâneos para aqui se fixarem em negócios do comércio ou algum outro tipo de trabalho. ${ }^{15}$

Já Valença chegou a possuir uma Delegacia Consular Portuguesa e uma Sociedade de Beneficência Portuguesa, citadas no Almanak Laemmert por sucessivos anos, sendo que esta última contava com a participação de vários membros, um dos quais, Custódio Antônio da Silva, redator e proprietário de um informativo local, o jornal —O Alagôas", foi segundo secretário da Sociedade por um bom período de sua existência. Isso comprova a importância da cidade como pólo de atração para os migrantes portugueses.

Entre os migrantes portugueses que se estabeleceram na cidade, encontrava-se Francisco Martins, originário da Ilha de São Miguel nos Açores, filho de Antônio Martins e de Ana Maria da Conceição. Não se tem registro da sua chegada exata ao Brasil nem das condições em que aqui aportou mas o mesmo, já em 1850, era proprietário de várias fazendas e possuía uma certa posição na sociedade em que vivia. Os Pimentéis procedem da Casa de Benavente, de dom Rodrigo Pimentel, que foi conde de Benavente e irmão do rei dom Afonso II. Entretanto, Francisco Martins, segundo interpretação que se dá ao fato de não assinar tal nome de família até o seu casamento, não era membro da família Pimentel e sim a sua primeira esposa, filha de Hipólito Pimentel e Joana Maria da Conceição, sesmeiros em Valença, uma das primeiras famílias a se instalarem no território. Com este casamento teria passado a assinar o sobrenome do sogro, sem que se saiba exatamente o motivo, e teve cinco filhos. Tal informação, no entanto, ainda não pôde ser comprovada, acreditando-se que ele era, também, membro

\footnotetext{
${ }^{14}$ Ibid., p. 161-162. O caso se assemelha ao de Manoel Esteves que também enriqueceu com o comércio e enviou o filho mais velho a estudar Direito em Recife.

${ }^{15}$ MARTINS, Roselene de Cássia Coelho. Colônias em Vassouras? Vassouras: s. ed., 2010, p. 4.
} 
da Família Pimentel, o que aqui não vem ao caso. Instalado, pois, em Valença, já no início do oitocentos gozava de certo prestígio na região. Foi ele o responsável pela construção de um dos quatro altares laterais da igreja matriz de Nossa Senhora da Glória, depois catedral-o altar dedicado ao Espírito Santo. ${ }^{16}$

Na região de Valença tornou-se um próspero fazendeiro. Sua atividade não ficou, porém, restrita ao campo. Contribuiu financeiramente para a construção de uma enfermaria destinada aos doentes pobres, subscreveu $400 \$ 000$ para a causa legalista na Revolução Liberal de 1842 e, mais tarde, com 500\$000 para os esforços da Guerra do Paraguai. ${ }^{17}$ Casou-se em segundas núpcias com Clara Maria Dutra, irmã da Baronesa de Santa Justa e descendente de antigas famílias do Vale do Paraíba, pertencentes aos primeiros grupos que se fixaram na região, em especial em Vassouras, sendo filha de Manuel da Silveira Dutra e de Maria Ignácia da Conceição, com quem teve, entre outros filhos, Maria Francisca das Dores, que viria a se casar com outro português, o futuro Comendador Manoel Antônio Esteves. Outro de seus filhos que merece um destaque especial foi Joaquim Gomes Pimentel, mais tarde agraciado pelo rei de Portugal com o título de Visconde de Pimentel.

Vale a pena abrir um parêntesis para destacar que Joaquim Gomes Pimentel realizou notáveis benfeitorias em sua propriedade, visando não somente a novas técnicas para o beneficiamento do café, como a melhores condições de vida para seus escravos. Sua fazenda recebeu uma visita do Conde D`Eu e nela instalou uma Escola de Ingênuos, onde escravos e crianças pobres aprendiam, além das primeiras letras, música, artes teatrais e religião. Mantinha também uma banda de música constituída por escravos libertos que se apresentava tanto nas festas da fazenda como nos acontecimentos sociais de Valença. Em sua casa, hospedou o grande pianista alemão Gottschalk ${ }^{18}$. Foi casado com Rita Leopoldina de Oliveira. Ele organizou um "Álbum de recortes de jornal e impressões de viajantes da fazenda Vista Alegre", de sua propriedade, fato esse citado por Ana Mauad ${ }^{19}$, no qual recolheu as notícias publicadas nos jornais da região e do Rio de Janeiro sobre si, seus feitos e sua fazenda, construindo, segundo a autora, a sua autoimagem.

Tudo isso parece ir de encontro à própria construção da imagem do país que se estruturava no II Reinado, recontando a história pátria, “...enfatizando os heróis de cada época. Foi assim que D. Pedro I, por exemplo, passou a montar um belo cavalo (e não uma mula) na cena do grito do Ipiranga ‘"20.

\footnotetext{
${ }^{16}$ Cf. FERREIRA, Luiz Damasceno. Valença, s. ed. 1978, p. 43.

${ }^{17}$ Cf. JANNUZZI, Fernando Antônio Ielpo Jr. Antigas Famílias de Valença-V. Gazeta Valenciana, 23 a 30 de outubro de 1999, p. 4.

${ }^{18}$ Apesar de sua atuação e das obras que promoveu, o título de Visconde de Pimentel foi recebido do rei de Portugal, não tendo ele, apesar de membro da Guarda Nacional, recebido qualquer titulação brasileira..

${ }^{19}$ Cf. MAUAD, Ana Maria. Imagem e autoimagem no Segundo Reinado. In: ALENCASTRO, Luiz Felipe de (org.). História da Vida Privada no Brasil. Império: a corte e a modernidade nacional. São Paulo: Cia das Letras, 1998, p. 212

${ }^{20}$ WITTE, Claudia Thomé. Dom Pedro II. In: AMARAL, Sonia Guarita do (org.). O Brasil como Império. São Paulo: Cia Editora Nacional, 2009, p. 179
} 
Entre as notícias a respeito de Joaquim Gomes Pimentel, destacam-se, entre outras, a que informa que ele ofereceu "uma variedade de grama de sua fazendall para o - embelezamento do jardim do Campo da Aclamação"21; a próxima inauguração de uma escola para ingênuos, em número de 30, - franqueando-a também aos meninos pobres da vizinhançall, além de já ter contratado professor" 22 ; a inauguração da dita escola em 25 de novembro de 187923; além de trazer na "primeira página o retrato do benemérito cidadão brasileiro o Sr. Visconde de Pimentel, fazendeiro do município de Valença”, comentando que em suas fazendas existia uma - elegante e bem construída capela, um teatro, uma banda de música, uma escola para ingênuos, bonds, tudo nas melhores condições de asseio, comodidade e bom gosto". 24

Essas e outras notícias de diversos jornais demonstram o cuidado mantido pelo Visconde de Pimentel em organizar a sua imagem. Ainda a respeito da escola dos ingênuos, consideramos interessante a notícia publicada em 1879 a respeito de sua futura inauguração, comentando que o —sr. Otaviano Hudson ofereceu 50 exemplares do seu método à mesma escola". ${ }^{25}$

O Visconde de Pimentel mantinha ligações estreitas com o país de origem do pai, tendo recebido sua titulação exatamente por serviços prestados a Portugal, dos quais encontramos, por exemplo, notícias a respeito de doações feitas à Comissão central de socorros às vítimas das inundações deste país em 1877, posteriores à homenagem recebida, entretanto:

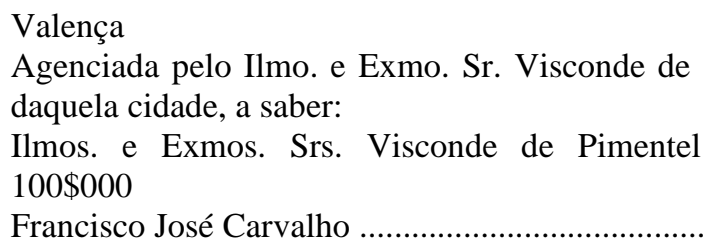
$400 \$ 000^{26}$

E a respeito do título recebido: “Concedeu-se licença a Joaquim Gomes Pimentel para aceitar e usar do título de visconde de Pimentel, com que foi agraciado por Sua Majestade Fidelíssima". ${ }^{27}$ Apesar de ter sido Joaquim Pimentel capitão da Guarda Nacional e de ter prestado notáveis serviços à região, logrando o reconhecimento de importantes jornais da capital da província e mesmo de outras regiões do país, ele não recebeu nenhum título nobiliárquico no Brasil. A sua titulação era, como dito, de origem portuguesa, concedida pelos serviços que prestara ao país de origem de seu pai.

\footnotetext{
${ }^{21}$ Gazeta de notícias, 03de janeiro de 1878.

22 Jornal do Commercio, 11 de novembro de 1879.

${ }^{23}$ Jornal do Commercio, 28 de novembro de 1879.

${ }^{24} \mathrm{O}$ Mequetrefe, 02 de junho de 1880.

${ }^{25}$ Gazeta do Norte, 11 de outubro de 1879

${ }^{26}$ Jornal do Commercio, 25 de maio de 1877.

${ }^{27}$ Jornal do Commercio, 22 de abril de 1874.
} 
Os portugueses residentes no vale no século XIX gozavam de bom prestígio e não deixavam de prestar sua colaboração quando necessário. Por ocasião da Guerra do Paraguai, por exemplo, foi formada uma comissão para angariar fundos para o Asilo dos Inválidos da Pátria: "Na Freguesia da Glória os súditos portugueses nomearam uma comissão para agenciar donativos para o Asilo dos Inválidos da Pátria e de fato realizou ela a quantia de $1.920 \$ 000 " .{ }^{28}$ Da comissão faziam parte o Comendador Agostinho José Vieira (importante comerciante local), Anastácio José Gonçalves Figueira (fazendeiro), Antônio Ferreira da Rocha (fazendeiro), Manoel Antônio Rodrigues Guião (fazendeiro), Manoel Antônio Esteves e Manoel José da Conceição Terra. Manoel Esteves, de quem falaremos mais adiante, aparece aqui participando de forma ativa da vida da região em que se fixou. Ainda sobre a Guerra do Paraguai, o memorialista elenca uma lista de doadores "que ofereceram donativos e prestaram serviços ao Governo", destacando-se os filhos de Francisco Pimentel e alguns portugueses. Da relação feita por Damasceno, tiramos:

- Joaquim Gomes Pimentel - com a quantia de 500\$ réis;

- Jacinto Martins Pimentel - com a quantia de 550\$ réis;

-Anastácio José Gonçalves Figueira (português) - com a quantia de 100\$ réis;

-Manoel José da Costa (português da Freguesia de Santa Teresa) - com a quantia de 50 réis.

Esse mesmo memorialista ainda explicita a existência, desde 1868, da Sociedade União Portuguesa de Beneficência, criada em 24 de maio de 1868, cujo fundador foi José Mendes Duarte. Sua diretoria foi composta, em 1871, de José de Almeida Ribeiro Júnior, como presidente; Antônio José Moreira Quintas, vice-presidente; Custódio Antonio da Silva, o já citado redator do jornal “O Alagôas", tesoureiro. Ainda faziam parte dela, como médicos, os doutores Luiz Alves de Souza Lobo e José Vieira dos Santos e tinha como advogado José de Rezende Teixeira Guimarães ${ }^{29}$. Se reiteramos a figura de Custódio Antonio da Silva e seu jornal é pelo fato deste informativo, pela análise das notícias veiculadas, ter sido, ao que tudo indica, um meio de projeção de seu redator e de notícias a respeito de seus patrícios, em especial de Manoel Antônio Esteves..

Custódio Antonio da Silva, em edição de 8 de maio de 1870 de seu jornal, por exemplo, afirma que a criação de uma sociedade de beneficência em Valença era uma necessidade, falando ainda de outras instituições congêneres espalhadas pelo país e de sua atuação, além de tentar esclarecer a índole dos portugueses fixados em Valença:

\footnotetext{
${ }^{28}$ FERREIRA, Luiz Damasceno. Op. cit., p. 263

${ }^{29}$ FERREIRA, Luiz Damasceno. Op. cit., p. 18.
} 
Ora, estando provado como está, que a índole Portuguesa é sobejamente benfazeja, impossível seria até que a pequena fração de Portugueses que residem nesta cidade não tivessem desenvolvido entre eles esse sentimento nobre e humanitário.

(...)Nasceu pois a ideia de levar-se a efeito um sociedade desse gênero em Valença, apesar de mil embargos e guerra mesmo que tinha de sofrer daqueles que dizem não precisarem para si, tendo em pouca conta o que na verdade é a caridade... ${ }^{30}$

Apesar de não residente na região, cabe ainda citar o Visconde de Condeixa, comissário de café que prestou seus serviços durante algum tempo para cafeicultores de Valença. Ele era também português, do ramo dos Colaços, João Maria Colaço de Magalhães Velasques Sarmento (1806-1871), com diversos títulos em Portugal e no Brasil. Um de seus clientes em Valença foi exatamente Manoel Esteves.

Originário da região do Minho, veio para o Brasil provavelmente na primeira metade do oitocentos, estabelecendo-se, por primeiro, na cidade de Vassouras, como comerciante. Tendo contraído matrimônio com a filha de Francisco Pimentel, transferiu-se, oportunamente, para a Fazenda Santo Antônio do Paiol, recebida como dote de casamento. Antes, porém, realizou benfeitorias, sem dúvida devido à abolição do tráfico de escravos, ocorrida exatamente no ano de seu casamento. Podemos deduzir tal afirmativa pelo fato de ter construído, na fazenda, uma enfermaria e uma farmácia para os escravos prezando, por conseguinte, o investimento feito com a aquisição destes.

Foi Esteves responsável pela construção de um ramal da linha férrea que, passando diante de sua fazenda, ligava Valença com o ramal do distrito de Juparanã e, daí, com a Pedro II. Isso contribuiu para melhorar e agilizar o transporte do café na região. Por tal iniciativa acabou recebendo a comenda da Ordem da Rosa. O jornal "O Alagôas", inclusive, cita Esteves como o único capaz de levar adiante tal empreitada. ${ }^{31}$ Foi ele, ainda, eleito provedor da Irmandade da Santa Casa de Misericórdia de Valença.

Enfim, notamos que vários desses elementos - Francisco e Joaquim Pimentel, Custódio Antônio da Silva e Manoel Esteves - estiveram, de uma forma ou de outra, ligados entre si. Isso leva-nos a acreditar que o tapete das sociabilidades portuguesas no Vale do Paraíba Fluminense foi muito bem tecido, explicitando como agiam tais imigrantes em uma terra que já havia pertencido ao seu país e que, após a independência, poderia ter se tornado hostil a eles se não buscassem, estrategicamente, unir-se em torno de objetivos comuns.

\footnotetext{
${ }^{30} \mathrm{O}$ Alagôas. Ano II, 8 de maio de 1870.

${ }^{31} \mathrm{O}$ Alagôas. Ano I, 11 de outubro de 1868.
} 


\section{CONCLUSÃO:}

Pelo que foi visto podemos deduzir que os portugueses que passaram a chegar ao Vale do Paraíba Fluminense necessitaram organizar-se para se destacar na boa sociedade local através de uma série de estratégias de sociabilidade.

Tais elementos formaram um vínculo entre si e deixaram indícios, por seu comportamento, a respeito disso, demonstrando que não estavam ligados apenas por laços de parentesco mas também de interesse, no intuito de se destacarem e alcançarem a respeitabilidade da parte não apenas da população mas, principalmente, dos membros da elite cafeeira.

Notamos diversificadas estratégias utilizadas pelos portugueses que precisaram, em primeiro lugar, escapar da desconfiança que ainda existia passados os primeiros momentos após a independência do país. Isso era necessário ainda que já existissem vários desses elementos participando da sociedade e com boas ligações com cafeicultores locais, já que a atividade comercial, entre outros motivos, e que era a principal atividade a que se ligavam, provocava um certo sentimento de concorrência por parte dos brasileiros.

No entanto, com habilidade e boas estratégias, acabaram se impondo e alcançaram posições de respeito e de participação na boa sociedade cafeicultora do Vale do Paraíba Fluminense. 


\section{FONTES BIBLIOGRÁFICAS}

ALENCASTRO, Luiz Felipe de (org.). História da vida privada no Brasil. Império: a corte e a modernidade nacional. São Paulo, Cia das Letras, 1998.

AMARAL, Sonia Guarita do (org.). O Brasil como Império. São Paulo: Cia Editora Nacional, 2009. FERREIRA, Luiz Damasceno. Valença, s. ed., 1978.

GINZBURG, Carlo. Mitos, Emblemas, Sinais. São Paulo: Companhia das Letras, 2007.

JANNUZZI, Fernando Antônio Ielpo Jr. Antigas Famílias de Valença-V. Gazeta Valenciana, 23 a 30 de outubro de 1999.

MARTINS, Ismênia de Lima; SOUSA, Fernando. Portugueses no Brasil: Migrantes em Dois Atos. Rio de Janeiro: Muiraquitã, 2006.

MARTINS, Roselene de Cássia Coelho. Colônias em Vassouras? Vassouras: s. ed., 2010.

MATOS, Maria Izilda; SOUSA, Fernando de; HECKER, Alexandre. Deslocamentos e Histórias: os portugueses. Bauru: EDUSC, 2008.

SOUSA, Fernando; MARTINS, Ismênia.; MATOS, Izilda (orgs.). Nas duas margens. Os portugueses no Brasil. Porto: CEPESE, 2009.

\section{FONTES PRIMÁRIAS}

O Alagôas. Ano I, 11 de outubro de 1868.

O Alagôas. Ano II, 8 de maio de 1870.

Jornal do Commercio, 25 de maio de 1877.

Jornal do Commercio, 22 de abril de 1874.

Jornal do Commercio, 11 de novembro de 1879.

Jornal do Commercio, 28 de novembro de 1879.

O Mequetrefe, 02 de junho de 1880.

Gazeta do Norte, 11 de outubro de 1879 